\title{
PRODUÇÃO DE DIESEL VEGETAL A PARTIR DO CRAQUEAMENTO TÉRMICO DO SABÃO DE SEBO BOVINO
}

Rayan Cristhian Viana Freitas ${ }^{1}$, Alcides Loureiro Santos ${ }^{2}$, Nadma Farias Kunrath ${ }^{2}$, Israel Silva de Souza ${ }^{2}$, Carlos Eduardo Garção de Carvalho ${ }^{3}$

1 Mestrando do Programa de Pós-Graduação em Ciências, Inovação e Tecnologia para a Amazônia da Universidade Federal do Acre (rayancristhian@gmail.com) Rio Branco-Brasil 2 Pesquisador (a) da Divisão de Tecnologia de Energia de Fontes Renováveis da Fundação de Tecnologia do Estado do Acre

3 Professor Doutor do Centro de Ciências Biológicas e da Natureza da Universidade Federal do Acre

Recebido em: 08/04/2016 - Aprovado em: 30/05/2016 - Publicado em: 20/06/2016 DOI: 10.18677/Enciclopedia_Biosfera_2016_149

RESUMO
Grande parte do desenvolvimento tecnológico da sociedade deve-se à utilização dos combustíveis fósseis. Porém, seu uso excessivo causa grandes danos ambientais. Nas últimas décadas, a procura por fontes alternativas de energia vêm crescendo significativamente. Os biocombustíveis são combustíveis derivados de biomassa, produzidos a partir de material vegetal ou animal. Uma das maneiras de se produzir esses combustíveis renováveis é pelo craqueamento térmico, processo que consiste na quebra das moléculas orgânicas longas em temperaturas acima de $350{ }^{\circ} \mathrm{C}$. Mesmos materiais residuais, como o sebo bovino, podem ser utilizados como matéria-prima nesse processo. Esse resíduo animal apresenta baixo valor econômico e nem sempre é descartado de maneira correta no ambiente. Diante disso, o objetivo deste trabalho foi produzir diesel vegetal de sebo bovino por meio do processo de craqueamento térmico e avaliar a qualidade do biocombustível obtido. Inicialmente, foram realizadas análises físicas e químicas do sebo bovino, para a posterior produção de sabão. Em seguida, o material saponificado foi seco e submetido ao processo de craqueamento térmico, sendo que a fração principal (diesel vegetal) também foi analisada. A acidez do sebo bovino alcançou o valor de $16,21 \mathrm{mgKOH} / \mathrm{g}$, considerada alta, entretanto o diesel vegetal produzido no craqueamento do sabão deste sebo, apresentou baixa acidez, 0,96 mgKOH/g. $\mathrm{O}$ rendimento do processo em diesel vegetal foi de $42 \%$ e as outras frações foram: coque $30 \%$, água $14 \%$ e gases $14 \%$. Com isso, os resultados foram considerados bons quando comparados com outros estudos que não realizaram a saponificação antes da reação de craqueamento.

PALAVRAS-CHAVE: craqueamento, diesel vegetal, sebo bovino.

\section{DIESEL PRODUCTION PLANT FROM THE THERMAL CRACKING OF BEEF TALLOW SOAP}

\footnotetext{
ABSTRACT

Much of the technological development of society is due to the use of fossil fuels. However, excessive use causes major environmental damage. In recent decades, 
the search for alternative energy sources are growing significantly. Biofuels are fuels derived from biomass, produced from vegetable or animal material. One way to produce these renewable fuels is the thermal cracking process comprising the breakage of long organic molecules to temperatures above $350^{\circ} \mathrm{C}$. Same waste materials, such as beef tallow can be used as feedstock in this process. This animal waste has low economic value and is not always disposed of correctly in the environment. Thus, the objective of this work was to produce diesel vegetable beef tallow through the thermal cracking process and evaluate the quality of the obtained biofuel. Initially, physical and chemical analyzes were performed beef tallow, for the subsequent production of soap. Then, the saponified material was dried and subjected to thermal cracking process; with the main fraction (vegetable diesel), it was analyzed. The beef tallow obtained an acidity of $16.21 \mathrm{mg} \mathrm{KOH} / \mathrm{g}$, considered high, however the vegetable diesel produced in this tallow soap cracking, had low acidity, $0.96 \mathrm{mg} \mathrm{KOH} \mathrm{/} \mathrm{g.} \mathrm{The} \mathrm{process} \mathrm{yield} \mathrm{in} \mathrm{vegetable} \mathrm{diesel} \mathrm{was} 42 \%$ and the other fractions were: coke $30 \%$, water $14 \%$ and $14 \%$ gas. Thus, the results were considered excellent when compared with other studies that did not undergo the saponification before the cracking reaction.

KEYWORDS: cracking, diesel plant, beef tallow.

\section{INTRODUÇÃO}

A sociedade moderna deve, em parte, seu grande progresso tecnológico e mecânico aos combustíveis fósseis, tanto como fonte de energia, como base de matérias-primas para o desenvolvimento de milhares de produtos. Em 2013, segundo a Agência Internacional de Energia (AIE), 31\% da energia que foi consumida no mundo foi derivada do petróleo (Gráfico 1), representando a maior parcela quando comparada com outras fontes (AIE, 2015). Entretanto, é importante ressaltar que o petróleo é uma fonte finita, limitada e não renovável, emitindo todos os anos milhões de toneladas de gás carbônico $\left(\mathrm{CO}_{2}\right)$ na atmosfera (MENEGUETTI et al., 2013).

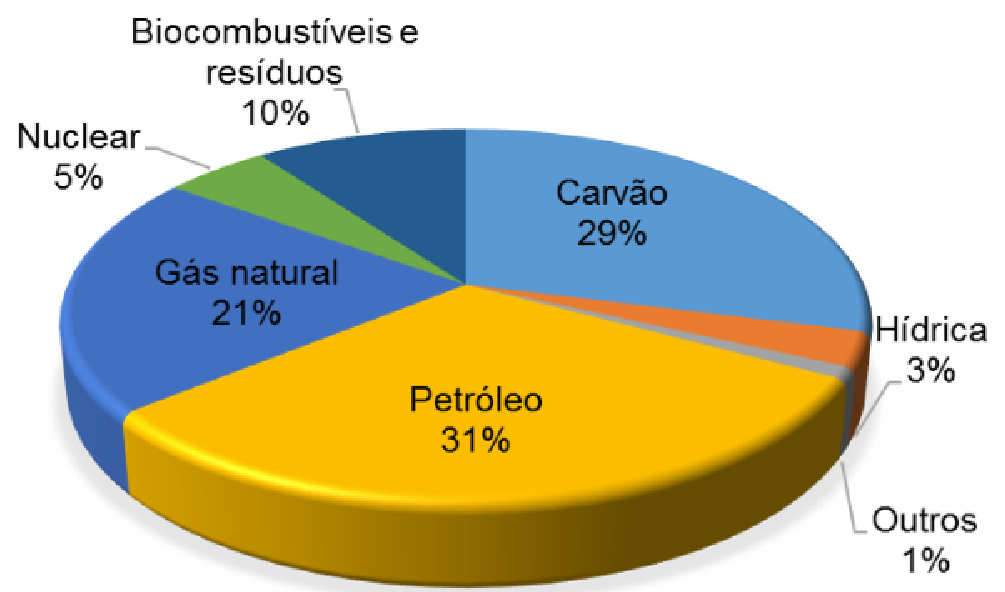

GRÁFICO 1 - Matriz mundial de energia de 2013.

FONTE: AIE (2015).

A procura por fontes alternativas de energia para substituição total ou parcial dos derivados do petróleo tem se tornado cada vez maior, não somente devido ao aspecto econômico, mas também em relação à questão ambiental (SANTOS et al., 2014). Diante disso, a cada dia vem crescendo a necessidade do desenvolvimento de novas pesquisas sobre os biocombustíveis. No cenário mundial, um dos países 
que vem se destacando como um dos maiores produtores de combustíveis renováveis é o Brasil, motivado pela sua grande extensão territorial, fatores climáticos favoráveis e políticas públicas de incentivo ao setor (BARCELLOS \& PEREIRA, 2015).

Nesse sentido, o etanol e o biodiesel são os principais biocombustíveis produzido no país. Segundo SILVA \& FREITAS (2008), o biodiesel é produzido basicamente a partir de óleos vegetais ou gorduras animais. As principais vantagens desse biocombustível estão no fato do mesmo ser biodegradável, não tóxico e renovável. Além disso, o biodiesel pode ser misturado ao diesel fóssil em qualquer proporção, apesar de que misturas majoritárias de biodiesel ainda trazem problemas em motores de ciclo diesel (PEREIRA et al., 2012).

No Brasil, para uso comercial, está em vigor a mistura B7 (7\% de biodiesel ao diesel). Entretanto, em outubro de 2015, através da resolução no 3 do Conselho Nacional de Política Energética (CNPE), o Governo Federal autorizou o uso e comercialização de misturas de biodiesel em quantidades superiores ao percentual obrigatório (BRASIL, 2015). Pela resolução, que ainda precisa ser regulamentada pela Agência Nacional de Petróleo, Gás Natural e Biocombustíveis (ANP), o percentual máximo de uso de biodiesel (transesterificado) varia de acordo com o uso dos veículos e máquinas. Os limites ficaram assim estabelecidos:

- B20: Frotas cativas ou consumidores rodoviários atendidos por ponto de abastecimento;

- B30: Transporte ferroviário, uso agrícola e industrial;

- B100: Uso experimental, específico ou em demais aplicações.

Apesar dos benefícios relacionados à utilização do biodiesel, SANTOS et al. (2015) comentam sobre algumas desvantagens inerentes ao seu uso em motores, como por exemplo, a maior emissão de óxidos de nitrogênio (NOx), menor poder calorífico e maior desgaste de alguns componentes do motor.

Existem vários processos para obtenção de biodiesel, sendo o mais utilizado atualmente, a transesterificação, seguido pelo craqueamento (TAPANES et al., 2013). SANTOS et al. (2015) falam que nas reações de transesterificação (Figura 1) os triglicerídeos, que são moléculas presentes em todos os óleos e gorduras animais, reagem com um álcool simples, metanol ou etanol, na presença de um catalisador, formando ésteres, metílico ou etílico, que constituem o biodiesel e a glicerina, esta subproduto da reação.
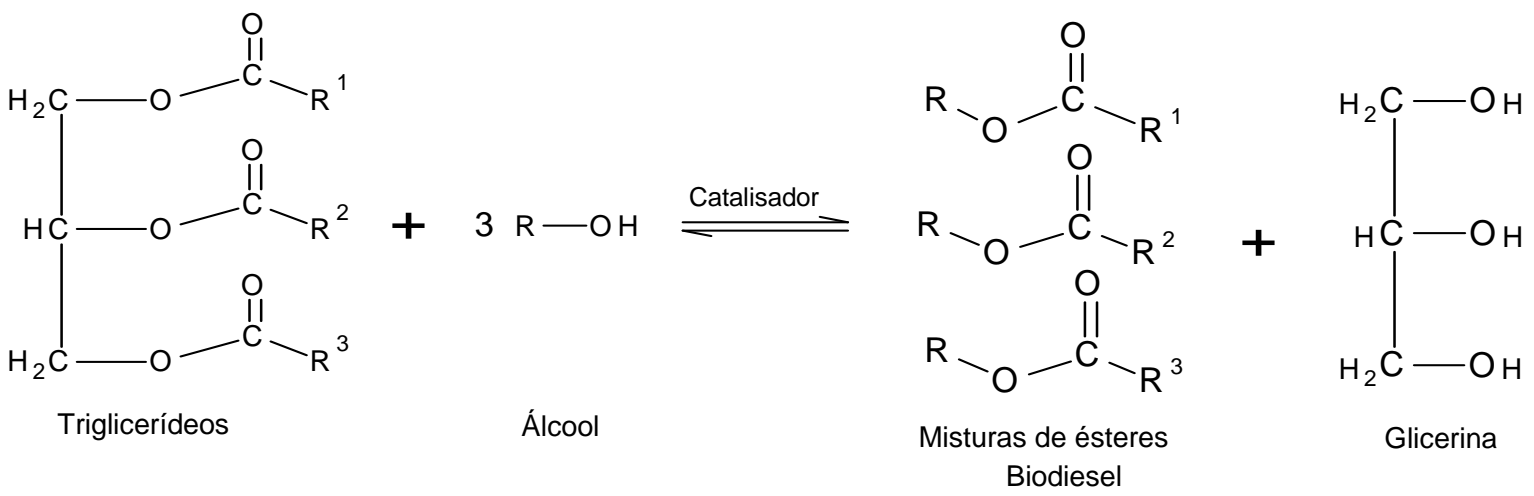

$R^{1}, R^{2}, R^{3}=$ estruturas carbônicas de ácidos graxos

$R=$ grupo alquil do álcool (metil ou etil)

FIGURA 1 - Reação total de transesterificação.

Fonte: Autores 
TAPANES et al. (2013) descrevem que o craqueamento consiste na quebra das moléculas presentes no óleo vegetal e gordura animal em temperaturas acima de $350 \stackrel{\circ}{ } \mathrm{C}$. Este processo ocorre na presença ou ausência de catalisadores, levando à formação de uma mistura de compostos químicos com propriedades semelhantes às do diesel, gases e gasolina de petróleo, que podem ser usados diretamente em motores convencionais, desde que atenda normas específicas (BOTTON et al., 2012).

SUAREZ et al. (2009) comentaram que na reação de craqueamento ocorre à formação de misturas de hidrocarbonetos e compostos oxigenados (Figura 2), tais como: alcanos, alcenos, cetonas, ácidos carboxílicos e aldeídos. Os autores também indicaram que a formação do biocombustível a partir do craqueamento termo catalítico depende de fatores como: temperatura, pressão, presença de catalisador, etc.

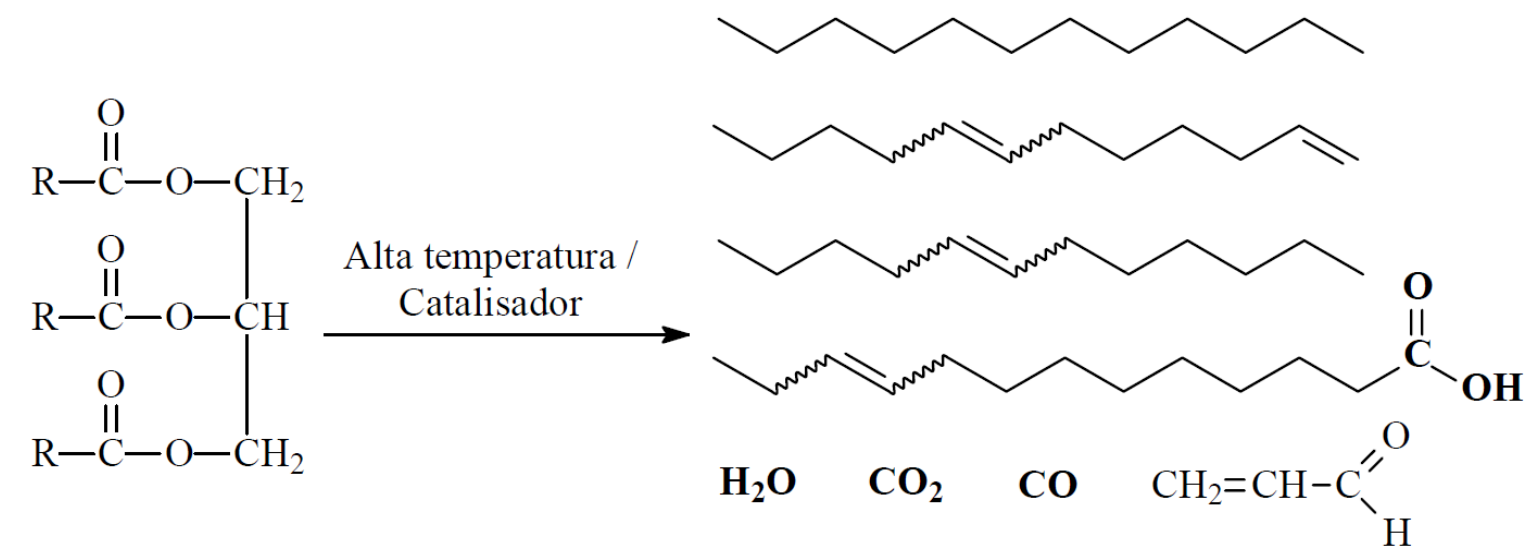

FIGURA 2 - Representação genérica da reação de craqueamento térmico.

Fonte: SUAREZ et al. (2009).

Principalmente devido à presença de ácidos carboxílicos, a fração líquida obtida do craqueamento geralmente apresenta altos valores de acidez e oxidação, inviabilizando sua utilização em motores de combustão interna. Porém, o craqueamento dos sais de ácidos graxos (sabão) gera frações formadas principalmente de alcanos e alcenos que, por serem hidrocarbonetos, são produtos com acidez baixa e mais adequados para os motores de combustão atuais (FORTES \& BAUGH, 1999). É importante destacar que a fração líquida do craqueamento pode ser chamada de biodiesel craqueado, diesel vegetal, diesel verde, entre outros.

PEREIRA et al. (2012) comentaram sobre a variedade de matérias-primas para produção de biodiesel, como óleos vegetais (soja, palma, girassol, algodão, amendoim e outros), gordura animal (sebo bovino, banha de porco, gordura de galinha, entre outras matérias graxas de origem animal) e pelo reuso de óleo (proveniente de frituras). Em especial, o sebo é um insumo obtido a partir do abate de animais, principalmente o bovino. $O$ aproveitamento deste refugo animal na produção de biocombustíveis, permite a expansão nas suas produções sem a concorrência com matérias-primas de caráter alimentício, como a soja (BARCELLOS \& PEREIRA, 2015). 
Diante disso, o objetivo deste trabalho foi produzir diesel vegetal de sebo bovino por meio do processo de craqueamento térmico e avaliar a qualidade do biocombustível obtido.

\section{MATERIAL E MÉTODOS}

O trabalho foi desenvolvido na Divisão de Tecnologia de Energia de Fontes Renováveis (DITER), da Fundação de Tecnologia do Estado do Acre (FUNTAC). O sebo utilizado é proveniente de frigoríficos do munícipio de Rio Branco (AC). De forma concisa, as etapas deste trabalho estão expostas no fluxograma da Figura 3.

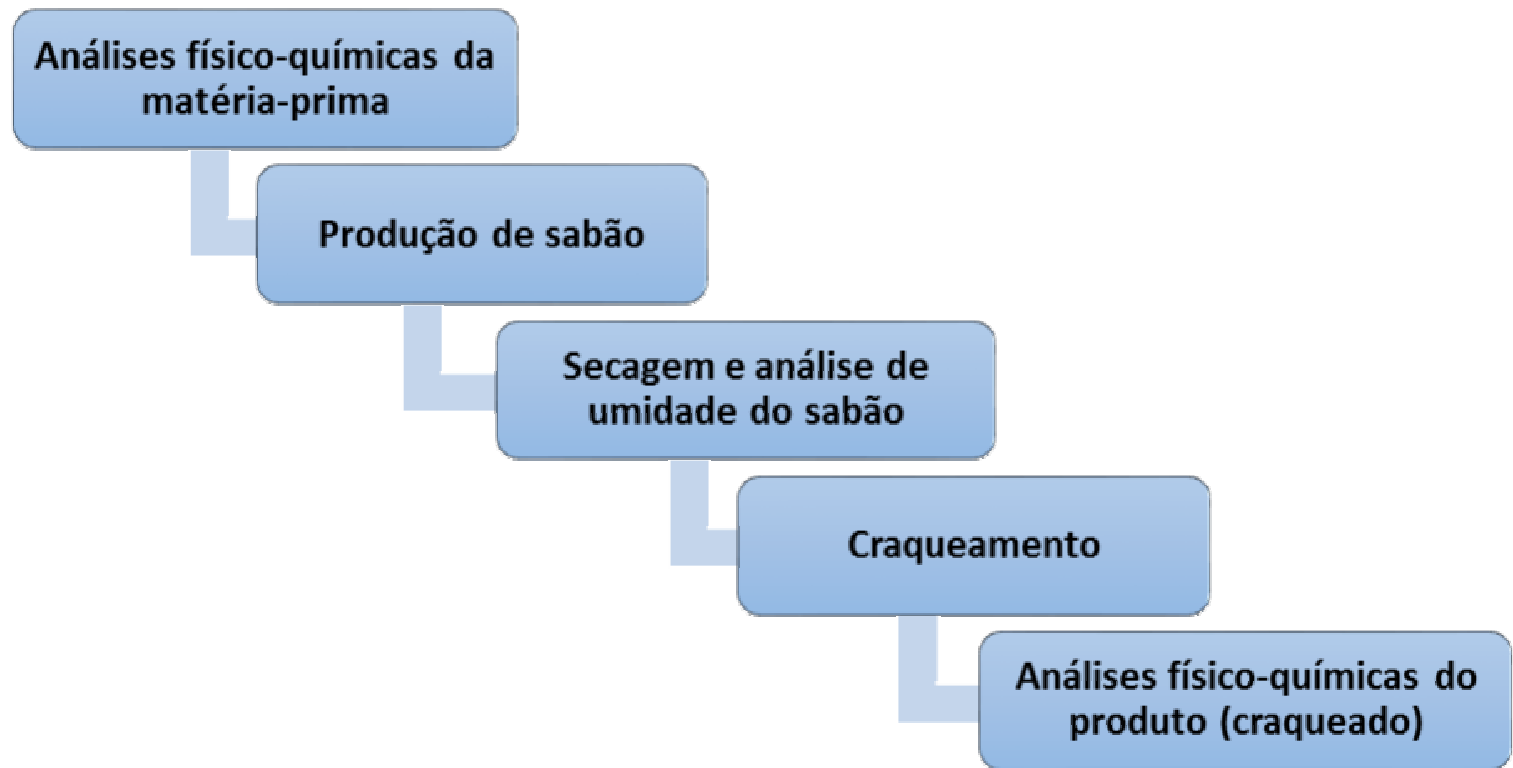

FIGURA 3 - Fluxograma de etapas da pesquisa realizada.

Fonte: Autores

\section{Etapa - Análise físico-química do sebo bovino}

As análises físico-químicas da matéria-prima foram: índice de acidez $(\mathrm{mgKOH} / \mathrm{g})$, índice de saponificação $(\mathrm{mgKOH} / \mathrm{g})$ e massa específica a $20{ }^{\circ} \mathrm{C}(\mathrm{g} / \mathrm{mL})$, realizadas tendo como base as normas ABNT NBR 14448:2005, ABNT/MB 75:1951 e ABNT NBR 7148:2001, respectivamente. Todos os ensaios foram realizados no Laboratório de Biocombustíveis da DITER.

\section{2a Etapa - Batelada de produção de sabão}

Para a batelada de saponificação (produção de sabão), $30 \mathrm{~kg}$ de sebo bovino foram adicionados em um reator encamisado com capacidade de $50 \mathrm{~L}$, acoplado a um agitador vertical, de acordo com a Figura 4. 


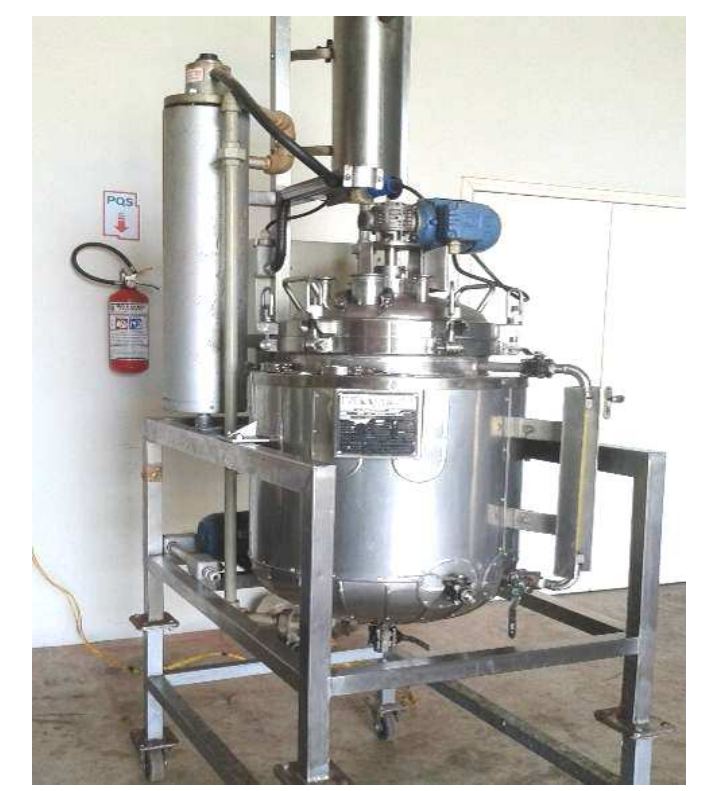

FIGURA 4 - Reator de processo encamisado de 50L. Fonte: Autores

Posteriormente, foi colocado ao reator, em mistura ao sebo, uma solução aquosa de hidróxido de sódio $(\mathrm{NaOH})$ na proporção de $10 \% \mathrm{~m} / \mathrm{m}$. A reação ocorreu na temperatura de $50{ }^{\circ} \mathrm{C}$, durante um período de 22 minutos.

\section{3 a Etapa - Secagem e análise de umidade do sabão}

O sabão foi colocado em bandejas para posterior corte e secagem ao ar livre. Ele passou por um período de secagem de 23 dias, sendo realizadas duas determinações semanais de teor de umidade, de acordo com a norma analítica ABNT/MB 80:1945.

\section{Etapa - Craqueamento}

A reação de pirólise ocorreu na unidade de craqueamento termo catalítico, em escala piloto, de acordo com a Figura 5.

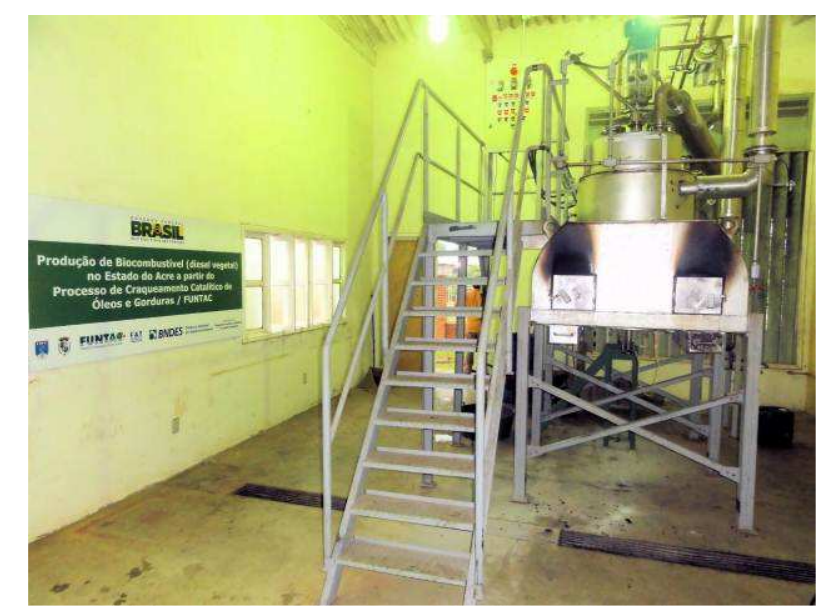

FIGURA 5 - Unidade de craqueamento termo catalítico.

Fonte: Autores 
Foi adicionada, à unidade de craqueamento, uma massa total de $33 \mathrm{~kg}$ do sabão de sebo. O processo teve duração de 6 horas e 40 minutos. Durante a reação, diversas medições de temperaturas foram realizadas em intervalos de 10 minutos, a fim de se estabelecer um perfil térmico do processo.

O produto líquido craqueado foi recolhido da unidade de condensação do equipamento, além disso foram separados os subprodutos do processo (água e coque) para calcular o rendimento reacional.

\section{5a Etapa - Análises físico-químicas do produto}

O diesel vegetal foi caracterizado através de análises de índice de acidez, de acordo com a norma ABNT NBR 14448:2005, viscosidade cinemática, norma ABNT NBR 10441:2007; e massa específica, baseado na norma ABNT NBR 7148:2001.

\section{RESULTADOS E DISCUSSÃO}

O sebo bovino utilizado neste trabalho foi caracterizado e os resultados das análises físico-químicas estão descritos na Tabela 1.

TABELA 1 - Resultados das análises físico-químicas do sebo bovino Análises Valores obtidos

\section{Referências}

\begin{tabular}{lcc} 
Índice de acidez $(\mathrm{mgKOH} / \mathrm{g})$ & 16,21 & $10,00^{*}$ \\
\hline Índice de saponificação $(\mathrm{mgKOH} / \mathrm{g})$ & 197,29 & $190-200^{*}$ \\
\hline Massa específica a $20^{\circ} \mathrm{C}(\mathrm{g} / \mathrm{mL})$ & 0,9065 & $0,8757^{* *}$
\end{tabular}

Fontes: *FIRESTONE, 2006. * ${ }^{*}$ SILVA et al., 2015.

O sebo utilizado apresentou um alto índice de acidez em sua composição. SANTOS et al. (2015) preconizam que um valor elevado de acidez inviabiliza a utilização em reações de transesterificação. Uma quantidade elevada de ácidos graxos livres reduz o rendimento da reação, além de elevar o número de etapas do processo (SANTOS et al., 2015). Todavia, para reações de craqueamento, que apresentam mecanismos reacionais diferentes, esse material pode ser utilizado, independente de sua acidez livre. Em relação ao índice de saponificação, observouse que o valor obtido estava de acordo com o que aponta a literatura. Ou seja, o sebo utilizado não é próprio para o processo de transesterificação, mas é adequado para o processo de craqueamento térmico, desde que seja realizada sua saponificação. A massa específica para o sebo utilizado neste trabalho foi ligeiramente menor que o encontrado na literatura, enquanto que o índice de saponificação encontrado está dentro da faixa esperada.

O sabão obtido a partir do sebo bovino passou por um período de secagem para redução de sua umidade. Esta, por sua vez, interfere negativamente no rendimento e na qualidade do diesel vegetal. No início da secagem, realizada de forma natural, o sabão apresentou umidade de $49 \%$ e, a partir de 16 dias esse valor se estabilizou em, aproximadamente, 11\%. Esse resultado mostra que a secagem natural ocorre de maneira lenta, indicando que a secagem artificial com circulação de ar pode ser mais indicada para produção contínua de diesel vegetal.

Durante o processo de craqueamento, foram medidas as temperaturas do reator e da entrada dos gases no condensador (Gráfico 2). 


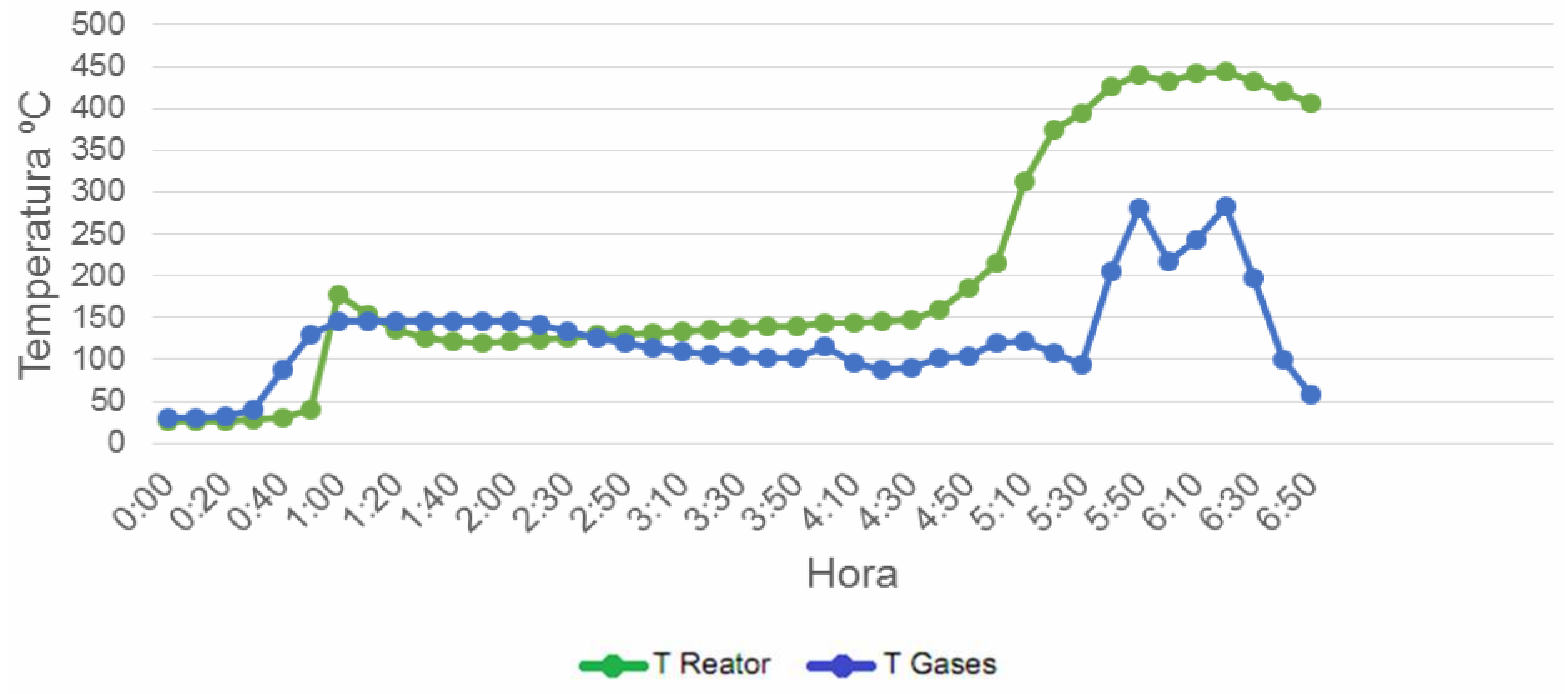

GRÁFICO 2 - Acompanhamento da temperatura do reator e dos gases em função do tempo.

Observa-se que a temperatura do reator (linha verde ou a curva mais acima no gráfico) manteve-se baixa nos primeiros minutos, logo após, apresentou tendência em manter-se constante quando atingia valores acima dos $100 \stackrel{\circ}{\circ} \mathrm{C}$ devido a vaporização da água presente no sabão. Após esta etapa, a temperatura teve crescimento acentuado e tornou a apresentar uma tendência de estabilidade quando alcançou valores acima dos $400{ }^{\circ} \mathrm{C}$, temperatura característica das reações de craqueamento.

A temperatura de entrada dos gases (linha azul, a curvas mais abaixo) se manteve inicialmente em temperatura ambiente. Posteriormente, esta apresentou valores constantes pouco acima de $100^{\circ} \mathrm{C}$, indicando a condensação dos vapores de água. Os picos apresentados a partir do tempo de 5:30, indicam as temperaturas registradas no ápice da reação. Foram recolhidas duas frações no tanque de condensação da unidade, uma aquosa e outra oleosa (Figura 6).

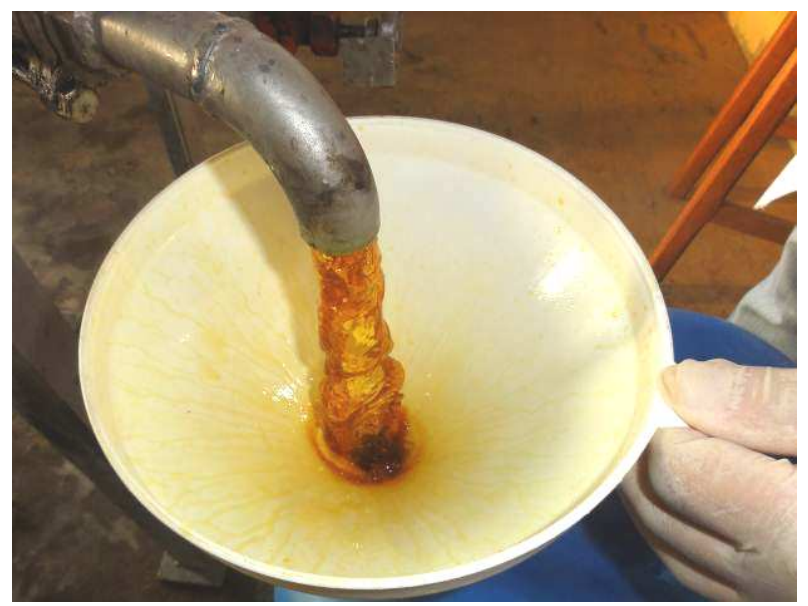

FIGURA 6 - Recolhimento da fração oleosa (diesel vegetal). Fonte: Autores

A fração aquosa correspondeu a $4,54 \mathrm{~kg}$, e, a fração oleosa (produto craqueado) apresentou massa igual a $13,92 \mathrm{~kg}$. Os gases de combustão e o coque ENCICLOPÉDIA BIOSFERA, Centro Científico Conhecer - Goiânia, v.13 n.23; p.1664 2016 
apresentaram massa de 4,60 kg e 9,94 kg, respectivamente. Os gases produzidos foram queimados em uma torre externa, sendo sua massa calculada pela balanço de massa do processo. O Gráfico 3 apresenta o rendimento mássico percentual do processo.

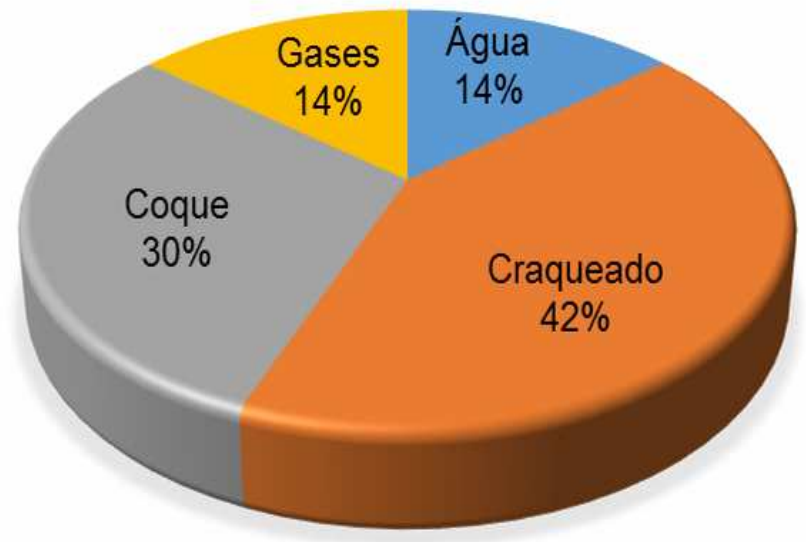

\section{GRÁFICO 3 - Rendimento do craqueado do sabão de sebo bovino.}

Foram realizadas análises físico-químicas do craqueado produzido e os resultados são apresentados na Tabela 2 , juntamente com suas comparações com os padrões estabelecidos pela ANP.

TABELA 2 - Resultados das análises físico-químicas do diesel vegetal (craqueado)
Análises
Diesel vegetal
Diesel* $^{*}$

\begin{tabular}{lcc} 
Índice de acidez $(\mathrm{mgKOH} / \mathrm{g})$ & 0,96 & Anotar \\
\hline Viscosidade cinemática $\left(\mathrm{mm}^{2} / \mathrm{s}\right)$ & 0,79 & $2-5$ \\
\hline Massa específica a $20^{\circ} \mathrm{C}(\mathrm{g} / \mathrm{mL})$ & 0,7912 & $0,81-0,86$
\end{tabular}

${ }^{*}$ Fonte: ANP, 2013.

Analisando os resultados, observa-se que o índice de acidez, obteve um valor baixo, comparando-se ao sebo bovino utilizado. Tudo indica que a saponificação da matéria-prima, devido às características alcalinas presentes em sua composição, neutralizam os ácidos graxos do sebo, fazendo assim, com que o produto final possua um baixo teor de acidez.

BOTTON et al. (2012) estudando o craqueamento termo-catalítico de óleo de fritura, analisado frações leves e pesadas do craqueado, obtiveram índices de acidez na faixa de 12,79 a $30,79 \mathrm{mgKOH} / \mathrm{g}$. Acredita-se que o processo de saponificação prévio da matéria-prima, permite a redução dos compostos de oxigênio na fase líquida e, consequentemente, melhora a qualidade dessa fração para fins de queima.

Os valores de massa específica e de viscosidade cinemática indicam que o diesel vegetal é mais leve que o diesel fóssil, podendo, possivelmente, adequar-se melhor em motores à gasolina (fração mais leve que o diesel). 


\section{CONCLUSÃO}

O craqueamento do sabão de sebo bovino demostrou ser uma técnica eficiente na conversão de gordura animal em biocombustível. Apesar da matériaprima ter um alto índice de acidez, em nada afetou na qualidade do produto final, isso foi possível devido ao processo de saponificação do sebo. O rendimento do produto líquido foi satisfatório, em relação aos demais subprodutos da reação (coque, água, gases). A saponificação da matéria-prima mostrou ser um método eficaz, produzindo um produto final com baixo índice de acidez devido às características alcalinas presentes em sua composição, neutralizando os ácidos graxos do sebo. Contudo, novos estudos com diferentes tipos de matérias-primas e catalisadores podem ser realizados em busca de diminuir as porcentagens dos subprodutos do processo, aumentando o rendimento da fração de diesel vegetal.

\section{AGRADECIMENTOS}

Banco Nacional de Desenvolvimento Econômico e Social - BNDES

Eletrobrás/Eletronorte - Centrais Elétricas do Norte do Brasil S/A

\section{REFERÊNCIAS}

BARCELLOS, L. S.; PEREIRA, R. G. Biodiesel de sebo bovino: um estudo bibliométrico. S \& G. Sistemas \& Gestão, v. 10, n. 1, p. 82-95, 2015. Disponível em: <http://dx.doi.org/10.20985/1980-5160.2015.v10n1.690>. doi: 10.20985/19805160.2015

BOTTON, V.; RIVA, D.; SIMIONATTO, E. L.; WIGGERS, V. R.; ENDER, L.; MEIER, H. F.; BARROS, A. A. C. Craqueamento termo-catalítico da mistura óleo de fritura usado-lodo de estamparia têxtil para a produção de óleo com baixo índice de acidez. Química Nova, v. 35, n. 4, p. 677-682, 2012. Disponível em: <http://dx.doi.org/10.1590/S0100-40422012000400004>. doi: 10.1590/S010040422012000400004

BRASIL. Agência Nacional do Petróleo, Gás Natural e Biocombustíveis - ANP. Resolução $n^{\circ} 50$, de 23 de dezembro de 2013. Regulam enta as especificações do óleo diesel de uso rodoviário, contidas no Regulamento Técnico ANP no 4/2013, e as obrigações quanto ao controle da qualidade a serem atendidas pelos diversos agentes econômicos que comercializam o produto em todo o território nacional. Diário Oficial, Brasília, DF, 24 dez. 2013. Seção 1, p. 104.

BRASIL. Conselho Nacional de Política Energética - CNPE. Resolução no 3, de 21 de setembro de 2015. Autoriza e define diretrizes para comercialização e uso voluntário de biodiesel. Diário Oficial, Brasília, DF, 14 out. 2015. Seção 1, p. 2.

FIRESTONE, D. Physical and chemical characteristics of oils, fats, and waxes. $2^{\underline{a}}$ ed., Washington - DC: AOCS PRESS, p. 204, 2006.

FORTES, I.C.P.; BAUGH, P.J. Study of Analytical On-line Pyrolysis of Oils from Macauba Fruit (Acrocomias clerocarpa M) via GC/MS. Journal of Brazilian Chemical Society, v. 10 n. 6, p. 469-477, 1999. Disponível em: <http://dx.doi.org/10.1590/S0103-50531999000600009>. doi: 10.1590/S010350531999000600009 
INTERNATIONAL ENERGY AGENCY. Key World Energy statistics. 2015. Disponível em: $<$ https://www.iea.org/publications/freepublications/publication/KeyWorld_Statistics_2 015.pdf>. Acesso em: 10 fev. 2016.

MENEGUETTI, N. F. S. P.; ZAN, R. A.; MENEGUETTI, D. U. O. Potencial do Sebo Bovino Rondoniense Como Matéria Prima para Produção de Biodiesel em Ariquemes RO. Revista Eletrônica em Gestão, Educação e Tecnologia Ambiental, v. 8, n. 8, p. 1889-1899, 2013. Disponível em: < http://dx.doi.org/10.5902/223611707636>. doi: 10.5902/223611707636

PEREIRA, C. M. P.; HOBUSS, C. B.; MACIEL, J. M.; FERREIRA, L. R.; DEL PINO, F. B.; MESKO, M. F. Biodiesel renovável derivado de microalgas: avanços e perspectivas tecnológicas. Química Nova, v. 35, n. 10, p. 2013-2018, 2012. Disponível em: <http://dx.doi.org/10.1590/S0100-40422012001000022>. doi: $10.1590 / \mathrm{S} 0100-40422012001000022$

SANTOS, A. L.; KUNRATH, N. F.; SOUZA, I. S.; CARVALHO, C. E. G. Avaliação Físico-química de Óleo Residual de Castanha-Do Brasil (Bertholletia Excelsa H.B.K.) e sua Conversão em Biodiesel. Enciclopédia Biosfera, v. 11, n. 22, p. 3550-3561, 2015. Disponível em: <http://dx.doi.org/10.18677/Enciclopedia_Biosfera_2015_064>. doi: 10.18677/Enciclopedia_Biosfera_2015_064

SANTOS, H.; JUNGER, D. L.; SOARES, A. B. Cascas de Arroz: Uma Alternativa Promissora. Orbital: the Electronic Journal of Chemistry, v. 6, n. 4, p. 267-275, 2014.

em:

<http://www.orbital.ufms.br/index.php/Chemistry/article/viewFile/612/pdf>.

SILVA, A. A. L.; SANTOS, A. G. D.; SOUZA, L. Di.; CALDEIRA, V. P. S.; LUZ, G. E.; ARAÚJO, A. S. P.J. Síntese e Caracterização de Biodiesel de Sebo Bovino e de sua Mistura B10. Orbital: The Electronic Journal of Chemistry, v. 7 n. 1, p. 21-27, (2015). Disponível em: <http://dx.doi.org/10.17807/orbital.v7i1.680>. doi: 10.17807/orbital.v7i1.680

SILVA, P. R. F. da; FREITAS, T. F. S. de. Biodiesel: o ônus e o bônus de produzir combustível. Ciência Rural, v. 38, n. 3, p. 843-851, 2008. Disponível em: <http://dx.doi.org/10.1590/S0103-84782008000300044>. doi: 10.1590/S010384782008000300044

SUAREZ, P. A. Z.; SANTOS, A. L. F.; RODRIGUES, J. P.; ALVES, M. B. Biocombustíveis a partir de óleos e gorduras: desafios tecnológicos para viabilizálos. Química Nova, v. 32, n. 3, p. 768-775, 2009. <http://dx.doi.org/10.1590/S010040422009000300020>. doi: 10.1590/S0100-40422009000300020

TAPANES, N. L. C. O.; ARANDA, D.A.G.; PEREZ, R. S.; CRUZ, Y. R. Biodiesel no Brasil: Matérias primas e tecnologias de produção. Acta Scientiae et Technicae, v. 1, n. 1, p. 119-125, 2013. 